\title{
Mixed methods evaluation of a menu of research learning opportunities for mid-career social work academics with 'protected time'
}

\author{
Lynn McDonald ${ }^{1}$, Claudia Bernard ${ }^{2}$, Donald Forrester ${ }^{3}$, \\ Sue White ${ }^{4}$, and David Shemmings ${ }^{5}$
}

\begin{abstract}
Knowledge about research methodologies and positive attitudes about research are each essential for academics who teach social worker students to advocate for and to deliver effective, empowering services to vulnerable people. This paper evaluates a menu of learning opportunities offered to fifty-two mid-career social work academics from 30 UK universities given 'protected time' to increase their research skills, funded by RDI4-ESRC. Qualitative and quantitative survey data are summarized. All participants attended five of eight conference days on research methodologies; 80\% participated in small discussion groups; $49 \%$ attended a 3-day writing retreat; $49 \%$ signed up to a research mini-placement; $31 \%$ presented research at a conference; $21 \%$ submitted manuscripts to a journal. The demonstrated commitment of time, expertise, and advanced skills to this project from 32 senior social science/social work researchers came at a time when media was blasting the profession. They modelled enthusiasm and confidence and 'bridged' access for the 'next generation' of academics. Repeated encounters amongst the participants gradually built 'bonded' social capital 'normed' positively around the enterprise of research. Participants reported at follow-up increased knowledge and confidence as they teach... In the current economic context, there are benefits of 'protected time' combined with structured opportunities for mid-career social work academics.
\end{abstract}

Keywords: RDI4; RDI; ESRC; quantitative; qualitative; attitude; data; professionals; interdisciplinary; social capital; teaching; experiential learning

1. Professor, Dept of Mental Health, Social Work and Interprofessional Learning, Middlesex University

2. Senior Lecturer in Social Work, Goldsmiths, University of London

3. Professor of Social Work Research, University of Bedfordshire

4. Professor of Social Work (Children and Families) University of Birmingham

5. Professor of Social Work, University of Kent

Acknowledgement: This article is based on the RDI-ESRC funding awarded to Middlesex University RES-046-25-0034

Address for correspondence: Professor Lynn McDonald, Department of Mental Health, Social Work and Interprofessional Learning, Middlesex University, The Archway Campus, Holborn Union Building, F. Block, 2-10 Highgate Hill, London N19 5LW.l.mcdonald@mdx.ac.uk

Date of publication (online): 20th November 2012 
To achieve the social justice goals of social work agreed by the International Federation of Social Work (IFSW, 2012), mid-career social work academics need current knowledge about research and evaluation methodologies, the skills to critique reports of effective social work interventions, and positive attitudes about the contributions of both quantitative and qualitative research. They teach the future professionals in the field. Social work and social care services are a vital component of public services in the UK. Well over 1.5 million people work in social work and social care services in the UK with more than $\mathrm{f} 14$ billion of public funds spent on social care services each year in England. Social care is a vital partner in health, child-care, education and criminal justice agendas, and, for example, can contribute to effective service delivery by offering respectful engagement strategies of low-income service-users (Freire, 1970) to gradually help address income disparities (McDonald et al., 2012).

But social work, as the discipline underpinning social work and social care research, has an historically weak research base. Relatively few funding resources are allocated to research the quality and impact of social work interventions with communities, groups, families, individuals, and the institutions serving socially marginalized and vulnerable populations. This low investment in social work research contributes to ongoing income and social inequalities (Saracostti, 2007; Wilkinson and Pickett, 2009).

The reasons for the deficit have been well documented (Mills et al, 2006; Orme $\&$ Powell, 2005; Fisher \& Marsh, 2003; Orme, 2003; Shaw et al, 2004; Shaw et al, 2006; Shaw et al, 2010). An additional practical factor which contributes to social work research deficits, is that within UK universities, there is often a lack of provision of 'chunks' of 'protected time' for academics to focus productively on their research. Instead, the work-loads of mid-career social work academics are often very heavy with teaching responsibilities, student meetings, tutor groups, supervised social work placements, extensive marking and double marking, and committee meetings, etc.

A competitive Research Development Initiative (RDI) award addressed these documented research capacity issues with funding by Economic and Social Research Council (ESRC). A menu of offerings was structured with opportunities for midcareer social work academics. These were only available to RDI participants if their University had provided 'protected time' in their workload for participation to further develop their research skills. This is the third RDI award for social work and was building upon the previous two RDI initiatives. The ongoing commitment of the ESRC to this issue, the collaboration of senior social work researchers in UK were used to successfully leverage 'protected time' from the universities.

This paper describes a menu of research learning opportunities developed for and offered to mid-career social work academics with 'protected time', including the takeup of the offers, and the qualitative and quantitative evaluation results from surveys of their experiences, followed by a discussion related to impact on their research knowledge, skills and attitudes. 


\section{Social Work Research Development Initiative (RDI4)}

In the current social historical context of social work in the UK, three RDI projects have now been completed, and this was the third RDI funded by ESRC to help raise the research profile of mid-career social work academics, in contrast to the extremely negative media about social work as a profession. In 2010-11, the social work research community was awarded funding to strengthen the research skills, knowledge and attitudes of mid-career social work academics. This was done in accordance with the social work research strategy in higher Education goals for 2006-2020 (JUCSWEC, 2006). This project was supported by the Joint University Council Social Work Education Committee (JUC SWEC) in collaboration with the Social Care Institute for Excellence (SCIE), the Scottish Institute for Excellence in Social Work Education (SIESWE) and the Social Work \& Policy (SWAP) HEA subject centre. Middlesex University lead this project with Universities of Bedfordshire, Birmingham, Goldsmiths, University of London and Kent.

Recommended mid-career social work academic participants (52) were provided sanction by their university (30) and 'protected time' for acquiring further research knowledge, skills and attitudes. Then, they were offered a menu of opportunities from which each could choose. The menu included small discussion groups led by RDI faculty, 3 day writing retreats hosted by RDI faculty, mini-research placements hosted by interdisciplinary senior researchers, and five conferences on research methodologies, with 32 senior researcher speaking to the participants. The project aims were to increase research knowledge, skills and confidence of mid-career social work academics. More specifically, aims were to shift attitudes about research to be more positive, to support and increase research writing and presenting skills, and to increase knowledge of a broader range of research methodologies.

For illustration, the research mini-placements were for 4-16 days done all at once or spread over time. These included such fascinating choices as 1) survey interviewing of middle class African-Caribbean families living in London (Institute of Education); 2) conducting a literature review of social work and mental health service users as part of a larger NIHR funded study (Medical School, Exeter University); 3) comparing outcome data for impacts of evidence based practices (EBP) (Dartington Social Science Research Unit); 4) helping to conduct a systematic literature review (SCIE); and 5) entering data from standardized instruments with established reliability and validity (e.g. Strengths and Difficulties Questionnaire-SDQ, Goodman 1997) from real parents and teachers on 7 year old children from a city in England, and then analysing the data with one tailed, paired t-tests using SPSS (Middlesex University).

Other research institutions that provided placements for the RDI participants were Tavistock Research Institute, Institute of Psychiatry, Goldsmiths, University of London, University of Bedfordshire, and Bristol University. Each of the miniplacements were negotiated, developed, written up, entered into a booklet and also published on the project website, from which the participants could choose. Some 
mini-placements were apparently more desirable than others and there was some competition, surprisingly; others were less appealing. Requests were made as to whether some could increase their capacity and take several RDI mid-career social work academics. The time-consuming contributions by senior researchers to further develop their research awareness, skills and confidence were well received by RDI participants.

The RDI4 project applied three adult learning strategies to help achieve these aims: giving choices, providing informal access and exposure to 'modelling' by senior research leaders in the field, and structuring research related, repeated positive social/professional encounters with one another as project participants:

1. Giving choices: professionals balance their precious time between work and life. When people make choices they have more ownership for the success of their choice. By offering choices to busy mid-career social work academics in a menu of opportunities, the participants could optimize the fit between their individual schedules and individual learning styles, e.g. listening to research lectures by one researcher after another at a conference; watching senior researchers teaching style as they discuss research methodology (modelling); going away for 3-day writing retreats; reading journal articles; participating in interdisciplinary research placements; faculty-led discussions about research and writing in small groups; presenting research papers to a safe audience of colleagues; and writing peer reviewed papers for publication.

2. Providing access to and exposure to senior social work/social sciences researchers, in which the senior researcher demonstrated their skills, competencies and attitudes. They acted as role models of enthusiastic, interesting people performing research actions and presenting new data, in a safe and informal academic seminar style environment, while also informing them on content about a range of social work research methodologies. Many of the 32 presenters had published books or articles assigned by the mid- career social work academics and were well known in the field. Some of the senior researchers were psychologists, sociologists and not social workers. Content was presented in an exclusive environment for only RDI participants, with an average of 35 attending each of 8 conference days. In addition, 22 respected researchers hosted research mini-placements, usually in large interdisciplinary federally funded projects. These placements offered midcareer social work academics to work alongside the senior researchers. These types of relationships could be considered 'bridging' across research professionals and across generations within social work research.

3. Building repeated encounters, which were research-related, positive, professional within the group of RDI participants from many universities. The hope is to develop a social network of mid-career social work academics with positive views about research. Repeated exposures over the year hopefully could result in 'feelings of being connected' and less isolated when it comes to research interests. A 
'social network' could support the growing professional enterprise of social work research on many levels, e.g. 'social norming' of research using a range of methodologies as a central social work function. Then, the question is how to find time, rather than whether to find time, to pursue research in addition to teaching, marking, supervision, managing, monitoring and for professionals the provision direct services. These types of relationships within the RDI participant group could be called 'bonding.' However, as they come from different universities, the relationships are also 'bridging' across departments of social work and universities.

\section{Evaluation methods}

The menu of research learning opportunities offered to the RDI4 participants from which they could choose was evaluated in two ways: first, we monitored how many participants selected which of the six opportunities. Second, a brief survey instrument of their opinions was developed with open-ended questions and a numeric scale. Specifically, the three questions were 1) What did you learn today (from this choice) about social work research that was helpful to you? 2) What was especially good about this (opportunity)? 3) What could be improved for future conferences (research learning projects)? In addition a quantitative measure of how participants rated the day (choice) overall was included. The scale ranged from 1 (bad) to 10 (excellent).

The survey was administered after each research learning opportunity on the menu: after each of five conferences, mini-placements, etc. In addition, an overall survey at the end of the RDI was sent out, in which the menu of opportunities could be rated reflectively and comparatively. Also, nine months after the final RDI conference, another survey with six questions for reflective feedback and sustainability was sent.

These results are presented in several formats. Qualitative data were analysed thematically with direct quotes from participants used to evidence and illustrate.

Quantitative data were analysed first separately and then combined. These data were entered into SPSS to both generate descriptive data used to depict impact and choices, as well as to calculate t-tests for differences. In addition, bar graphs and tables for these outcome data were developed and some data are presented in different ways to demonstrate how different they can look visually. The project aims were to increase research knowledge, skills and confidence of mid-career social work academics. More specifically, to shift attitudes about research to be more positive, to support and increase research writing and presenting skills, and to increase knowledge of a broader range of research methodologies. 


\section{Findings}

Participation rates of the choices made by the mid career social work academics of Menu of Opportunities: research opportunities offered had varying take-ups levels:

- $52(100 \%)$ attended at least five of the ten conference days offered on specific research methodologies: evaluation methodologies, 2-day; quantitative methodologies, 2-day; qualitative methodologies; risk and protective factors methods; and using mixed methods, 2-day. There were presentations made by 32 senior researchers from many disciplines. Between 15-45 attended any one conference;

- 32 (61\%) participants signed up and participated in one of four bi-monthly small discussion/support groups with each one led by one RDI faculty, to write research manuscripts/grant proposals.

- 25 (49\%) participants attended one of the two 'writing retreats' led by RDI faculty (3 days each) in June 2010 and June, 2011, with individual writing time, presentations, and group and on-site one to one consultations

- $22(42 \%)$ research mini-placements (4-16 days each) were supervised by senior researchers in interdisciplinary projects at universities/research institute, of the 25 opportunities offered without any exchange of funds. $49 \%$ enrolled in a mini-research placement, but matches were not made.

- $16(31 \%)$ made a formal presentation of a research paper or a poster session at the final RDI conference

- $11(21 \%)$ submitted research papers to a special issue of SWSSR

\section{Survey evaluation results}

Evaluation of the evaluation methodology conference. A total of 63 people attended the two-day conference on evaluation methodologies for social work, of which about 13 were senior researcher speakers, RDI faculty and staff. Of the social work mid-career academic participants, only 30 participants completed the evaluation form after the first day, and 26 did so after the second conference day. The forms were handed out at the conference, and also emailed to the participants afterwards. The response rate of RDI participants for evaluating the first two-day conference averaged just under $60 \%$. 


\section{Qualitative evaluation: Evaluation Methodology Conference}

\section{1) DAY ONE}

What did you learn today about social work research that was helpful to you?

Many participants expressed that what they had learned from the first day of the conference was 'how much is already taking place and the rich diversity of current social work research'. Useful learning also included understanding the setting and context within which social work research is carried out, such as the 'national priorities for research', the 'importance of evidence based practice' and the 'research and practice culture gap'. SCIE 'signposted some really useful content and resources'. Useful advice was also received 'about where to get funding for research from' and 'what direction we need to work in with regard to research'. Respondents expressed that they had learnt about the need for more and better research; 'it is something we should be 'pushing' [and] this initiative will help to do so' and 'more of it, and better quality, is needed now!' Many commented on the usefulness of their learning about evaluation methods and designs; 'I learnt about evaluation methods in a clear and down to earth way' someone commented and another participant reported, 'I plan to develop a partnership arrangement with my Local Authority in which we offer evaluation of specific projects/work packages, so these sessions were particularly enjoyable'.

Some useful learning had also taken place in terms of confidence and some commented that they had realised that other social academics also felt insecure about research: 'I am not the only one who feels inexperienced'; 'It gave me confidence to do social work research'; 'it was more about building a confident community than specific learning' were some of the feedback received.

What was especially good about the conference today?

Much positive feedback was received with regards to the appropriateness and quality of speakers on day one of the conference. What respondents in particular had valued was 'the good range of speakers', the 'range of perspectives offered by different presenters', the 'stimulating variety of speakers and topics' and the 'enthusiasm and passion of presenters'. Respondents expressed that they had been stimulated and inspired and as one participant phrased it 'I feel confident that the initiative will meet my needs'.

For many respondents the most valuable aspect of the day was the opportunity for 'networking', 'meeting other motivated academics' with 'similar aims, objectives and interests', and one participant described the sense of 'collective identity' present on the day. Participants also provided very positive feedback in relation to the learning sets, which were designed as a supportive group environment for the development of research ideas. 


\section{2) DAY TWO}

What did you learn today about social work research that was helpful to you?

Very many respondents reported on their feedback form that on day two of the conference they had learnt the 'the importance and challenges for service user involvement in research'. Comments in relation to the session on service user and carer research participation were that this had been 'interesting' and 'thought provoking', and someone reported that they had been 'updated on issues regarding service users [participation] in research'. Although, one participant had felt that the 'service user carer involvement sessions at times [was] too patronising'.

Participants also commented on the usefulness of the presentation focusing on research ethics such as 'the importance of addressing diverse issues in ethics applications'. Some had learnt how ethics 'links to research' and commented that this session had been 'very helpful', which is suggestive that research ethics was an unfamiliar territory for some social work academics.

What had been learnt also included applied research approaches and methods. Many reported that the day had had a useful 'focus on quantitative research and evaluation' and 'quantitative methods and analysis'. Some reported having learnt 'more about quantitative research using standardised instruments', about 'randomised controlled trials', 'how SPSS works', and someone commented that their learning had entailed the 'use and revision of stats'. In addition, many comments were also received with regards to mixed methods - 'how quantitative and qualitative can be combined', and the 'pragmatic approach' which covered the use of both quantitative and qualitative methods in social work research was highlighted. What was taken away from the day for some participants was how to appropriately and practically apply evaluation methods in research and the "use of certain methods in a real world setting, and someone reported to have learnt to 'relax about methods, [as the] question comes first'.

What was especially good about the conference today?

The opportunity for 'networking' and the 'chance to meet other academics' was again on the second day of the RDI conference day flagged up by respondent as being particularly valuable.

As on the first day, the second conference day received many positive comments about the quality and calibre of the speakers, and the 'good talks' were commented on by many respondents. The session on service user and carer involvement was highly commended by many.

Respondents expressed that they felt that over the two days they had come a long way and had developed in terms of their understanding, application and appreciation of research. Someone commented that they 'felt clearer on [the] second day about [a] range of methods and how they interact' and another reported to 'have a good understanding over [the] two days about evaluation'. Some clearly stated that they had felt encouraged in the sense that the conference had been an inspiration for 
getting on with research bids/writing', it had helped develop 'methodological ideas', and as expressed by one participant 'it fundamentally stimulated my interest in and motivation for research'.

What could be improved for future conferences for this ESRC RDI project? (Combining Day 1 and Day 2 qualitative responses by RDI participants)

Suggestions for improvement for future conferences were very similar for day one and day two of the conference. The majority of comments related to the administration and lack of information provided prior to the event and the 'timeliness and clarity' of this. One participant reported that participants' information had been 'misplaced' and was requested again; some participants had also been missed off the e-mail list and had received no information. One participant suggested that there was a need for 'better organisation, [and] thinking through participants needs'. Suggestions for improvements were related to the RDI project overall there was a need for 'clearer information prior to [the] conference about the entire project - I was not entirely clear about the information I received'. Concerns for the practical matters such as travel and accommodation were expressed: 'are applicants expected to self-fund travel to placement sites?' and 'more consideration of travelling time and arrangements for accommodation for those travelling from outside London'. Also, after the conference there was a request for more clarity on how to 'access the website, videos, workshops', and 'being clear where powerpoints and other materials are available'. Many participants also expressed that more information should have been available about the mini-placements.

Participants also commented on the timekeeping of the talks and workshop sessions; many workshops were reported to have overrun and this left less room for discussion and questions and 'talks in after-session was limited;' some requests for longer sessions would have allowed them to develop 'a better understanding and experience of [the] workshop;' and some asked future conferences to use 'less formal presentations.' Another issued was the necessity for participants to choose between three parallel workshops running that the same time. Because of this, some conference delegates fell that they had missed out and some would like 'more chance to get the range of workshops offered somehow'; 'I wanted to attend more of the breakout sessions!' a respondent expressed.

\section{Quantitative evaluation: Evaluation Methodology Conference}

Survey data (see Table 1) showed that on Day 1, Day 2 and Overall, the RDI participants were fairly positive in their rating of the conference. On a scale from 1 (bad) to 10 (excellent), participants' average rating were aggregated over the two conference days was 7.95, with a standard deviation (SD) of 1.257. When the same data are separated presented in bar graphs (see Figure 1), one has more information 
and one can see that the RDI participants on average rated conference day two $(\mathrm{M}=8.08$, SD 1.230) as a bit better than day one ( $M=7.83$, SD 1.289). However, visually the difference between them is minimal. This was confirmed with a t-test which revealed that this difference was not statistically significant $t(54)=-.72, \mathrm{p}>.4)$. However, if the same survey evaluation data are presented separately by day (see Figure 1) in bars graphs using an alternative standard for the left margin scale scores with less range, the differences on impact seem bigger.

Table 1:

Mean ratings of the two conference days

\begin{tabular}{lccc}
\hline & Mean & SD & N \\
\hline Rating day 1 & 7.83 & 1.289 & 30 \\
Rating day 2 & 8.08 & 1.230 & 26 \\
Rating overall & 7.95 & 1.257 & 56 \\
\hline
\end{tabular}

The same evaluation data can offer more information. In Figures 1, both bar graphs present the mean. Table 1, however, presents the mean and the standard deviation for Day 1, Day 2 and the Overall. In Figure 2, the additional data presentation depicts the standard deviation visually. This information provides the range of responses on the scale by the RDI participants. This is interesting for the hosts of the conference, as it shows the distribution of frequency of RDI responses for each number on the scale, and also the outliers who did not like it as much. Figure 3 presents both days separately, not aggregated, for the evaluation methods conference.

\section{Quantitative Evaluation: Menu of Research Learning Opportunities}

The RDI participants' evaluations were very positive, but there were still differences. The quantitative aggregated data from the evaluations of each of the five methodology conferences showed a steady improvement (see Table 2). The first conference was on evaluation research methodologies (Sept, 2010) and received a mean rating of 7.69 (see above for more detailed presentation). The second conference was on quantitative methodology (Feb, 2011) at 8.37; the third conference was on qualitative methods and social work research (Apr, 2011) and scores were 8.76; followed by the fourth on use of risk and protective factors theory in research (May, 2011) at 8.33; and then, the fifth conference was on use of mixed methodologies (Sept, 2011) and the evaluations peaked with a mean rating of 8.90 . 
Figure 1

Participant ratings for day 1 and day 2

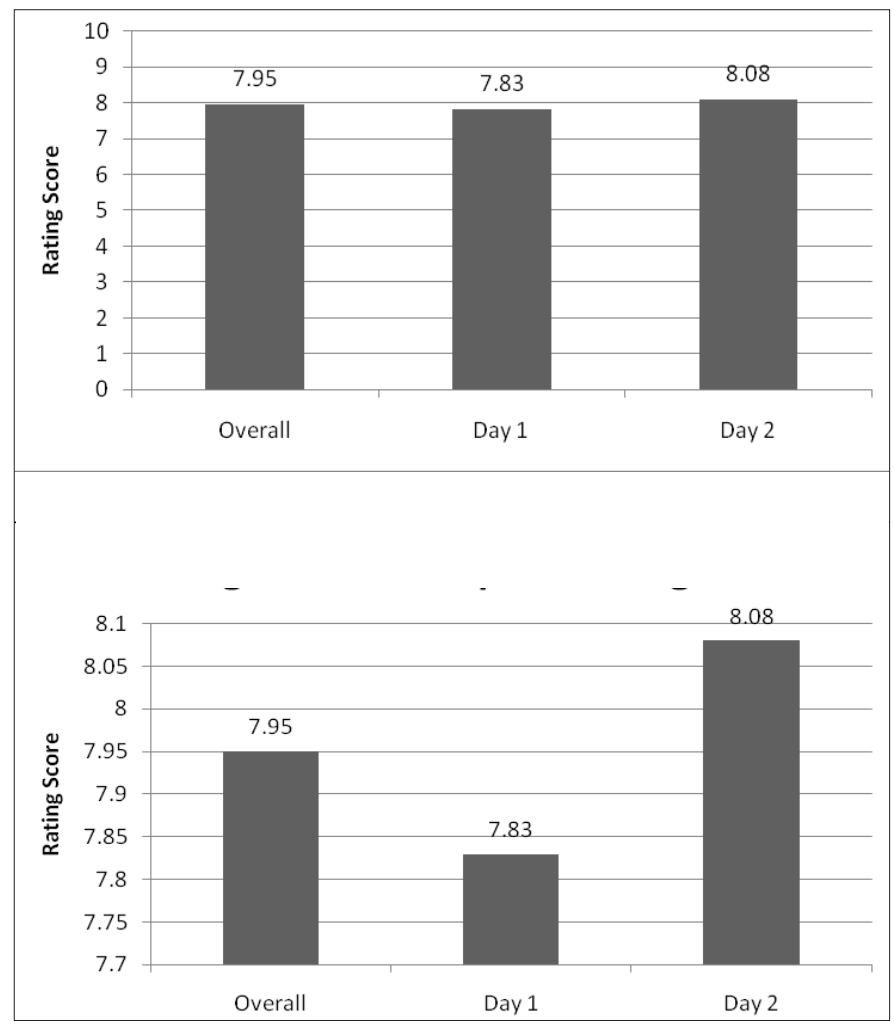

Figure 2

Participant ratings for day 1 and day 2

\section{Distribution}

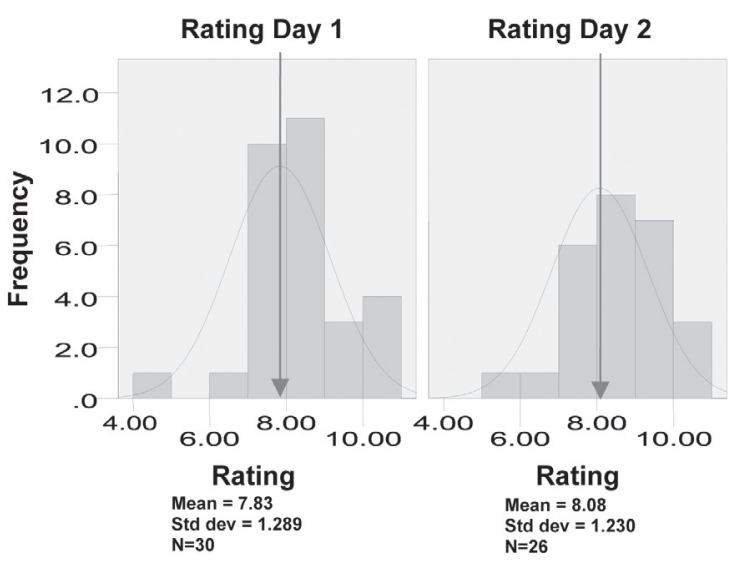


Table 2

Evaluations aggregates for five research methodology conferences

\begin{tabular}{lrrcccc}
\hline & $n$ & Range & Minimum & Maximum & Mean & SD \\
\hline Launch Conference & 23 & 8.00 & 2.00 & 10.00 & 7.6957 & 1.89340 \\
Experimental Methods & 16 & 3.00 & 7.00 & 10.00 & 8.3750 & 1.02470 \\
Qualitative Methods & 17 & 3.00 & 7.00 & 10.00 & 8.7647 & 1.14725 \\
Risk and Protective Theory & 3 & 5.00 & 5.00 & 10.00 & 8.3333 & 2.88675 \\
Mixed Methodologies & 22 & 3.00 & 7.00 & 10.00 & 8.9091 & 1.06499 \\
\hline
\end{tabular}

In addition, the writing retreats, the small discussion groups and the research miniplacements were evaluated as a part of the menu of learning opportunities offered. (See Figure 3 below). These evaluations supported the idea of different learning styles of RDI participants; those who chose a particular approach found benefits.

Figure 3

Evaluation of research menu of supportive learning sets:

Discussion groups, mini-research placements, and writing retreats

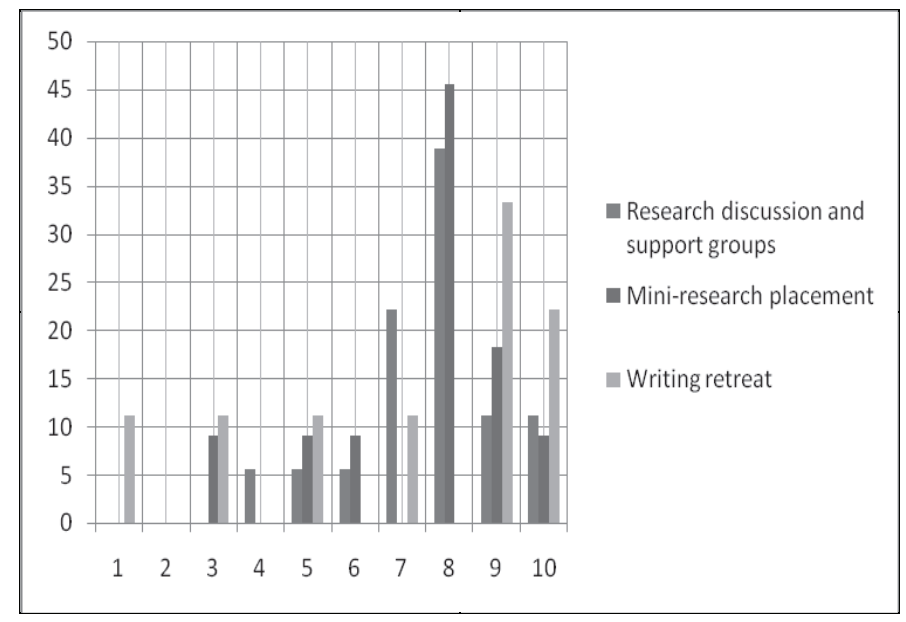

\section{Qualitative evaluation: Overall RDI4}

The overall qualitative findings were consistent with the quantitative evaluation data and reflect the positive impact that the RDI project had on participants. The data was not selective or contradictory as it appeared $100 \%$ of participants who completed the final evaluation forms were quite satisfied with the process. They commented that throughout the year long course they 'improved skills in writing, new methods, 
the value of evidence, being systematic and thoughtful', gained valuable information regarding the 'publishing processes' and 'evidence based research grant skills.' They also noted that throughout the conferences they had gained greater confidence in their abilities as researchers. The key benefit stated in the qualitative data pertained to networking and the 'excellent opportunity to disseminate knowledge' through associating with other academics, a process which many found both helpful and 'inspiring'. The comments received highlighted their enthusiasm and gratitude: 'Appreciate all of the hard work and opportunities you have provided.' 'I have been able to develop my writing skills based on my own small study. Probably would not have the confidence to do this without RDI especially as I used quant analysis'. These echo the words written by the vast majority of participants.

\section{Follow-up of RDI4 Sustainability}

After the RDI4 project ended, we sent out at nine months a follow-up questionnaire on the project impact. Those participants who responded reported still feeling more connected to one another, and less alone as social work researchers. They reported teaching research with more confidence. There were spill-over effects of the university social work departments which invested in them and protected their time for research of the 52 sponsored RDI participants from 30 universities. The universities have asked the RDI participants to share what they learned in various forums. The participants also highly recommended the initiative to others. In addition, they reported increases in writing research papers, presenting of papers, and submitting social work research bids, which is sustainability. See below are a few responses on sustained impact at 9 months and also more in Table 3.

--RDI increased confidence and commitment to social work research. Also created valuable contacts and networking. It remains difficult to increase research activity in the current climate in terms of teaching and admin responsibilities.

--This was a brilliant experience, it was so good to meet up with other tentative researchers from across the country, and find out that most of us felt lacking in confidence in being able to research and that for many of us, we had a feeling that we weren't 'proper' academics because we were practitioners turned academics - so we sometimes felt we had little 'authority' as 'would be researchers'. I learned a lot from other participants as well as from the programme organisers and presenters, and also learned that I had more capability and knowledge than I generally gave myself credit for. 
Table 3

Qualitative data: RDI4 evaluations at 9 month follow-up

1. Do you talk more about research with colleagues?

- Yes, I now build this in to my career development and deliberately set dedicated time aside as part of my working week

- Alas I do not read as much as I would like -whilst the RD14 increased my confidence I still lack time within my workload to do this!

- Definitely more confident -but still need to revisit materials and do follow up reading on some of the references given.

- Definitely

2. Do you teach more research related material to your social work students?

- Yes - it has provided me with a solid base from which I know I can build. It put aspects of research and the research process into context and dispelled some of the myths. Most importantly I learnt the importance of collaboration and engagement.

- Have been teaching the research module this year.

- Always taught it but now it's got a clearer focus and I've been developing my thinking about practitioner research (really relevant with PQ/CPD teaching) I've also been invited to teach specific topics related to evaluative research on our new MA programme

- Yes - I have been asked to teach research related materials and have also found it much easier to teach -especially regarding lit reviews and evidence based practice.

3. Do you write more research papers or research presentations or bids?

- Since RD14 I have contributed to 2 bids, presented 1 peer reviewed paper and written a book chapter on research in social work (for Sage). It has also helped me with my thinking and methodological approach to a PhD.

- It is my plan to do so

- I had my paper for the RDI4 special edition accepted with revisions and this taught me so much about professional writing - other papers in the pipeline now! I've also had the confidence to write book reviews (one published in SWESSR already - on practice-based research title)

- Continuing to work on papers with several 'in progress' at various stages.

4. Do you contact other RDI4 participants to keep connections going?

- I have not had phone contact but have seen participants at other conferences and we have shared work etc then. It was useful in establishing these links, especially with colleagues who at in approx. the same career stage as me. I found their reflections on teaching and workload balancing at other universities particularly helpful.

- Some contacts have been maintained.

- I have been in touch with one. I have also met another at a separate conference. I also hope to set up an interest group in image based methods for research and teaching social work

- Within our HEI - yes, those of us who participated are a closer group. Have had some correspondence with other participants but I think we all have heavy workloads!

5. Would you recommend it to others? To funders? To universities?

- -Without a doubt - the initiative should be built on in order to develop research capacity in social work. I think it would be good also to offer it to interested practitioners across the different areas of social work, not just to academics - though I'd not particularly like the task of trying to sell the idea to local authorities with staffing and budget difficulties.....

- -Yes, I would recommend it to colleagues. Social work research needs this additional input, particularly as many of us enter academia without a PhD -it provided a useful grounding for me.

- -Yes - to colleagues as well as funders and universities

- -Definitely 


\section{Discussion}

At the end of the project, the evaluation findings were presented at a meeting to the JUCSWEC social work academic researchers (London, Nov 2011). The senior social work researchers reported being quite pleased with the results, adding positive remarks in the JUCSWEC minutes. As co-sponsors of the RDI bid, this was good news.

The immediate feedback from the survey responses after each conference enabled the staff to make improvements. The pattern over the span of the RDI project of improved mean ratings reported after each of the five conferences on the survey scale score provided reinforcement for RDI staff's efforts to respond to feedback from each of the participants. For example, better time-keeping, funding for the cost of travel and hotels, the possible use of an on-line wiki to reduce costs, and the opportunity to involve other non-social work academics to broaden the scope.

Overall, a spirit of generosity was displayed by the senior social work researchers and researchers from other backgrounds from 35 universities and research centres. Their gifts of time towards further research development of the next generation of social work academics were central to the impacts identified in the evaluations.

- Thirty-two senior research academics from social work and social sciences either presented at a research methodology conference, and/or hosted a research mini-placement, and/or led 5-6 regular meetings of small support groups and/ or hosted two writing retreats.

- Twenty-two universities developed proposals research mini-placements; 20 hosted mini-placements for mid career social work academics (e.g. Dartington Social Research Unit in Devon; Tavistock Research Institute; Institute of Education; and Institute of Psychiatry).

- The peer-reviewed journal, Social Work and Social Science Research (SWSSR) editors invited two special issues to be edited by the RDI project faculty in order to further extend the impact of the ESRC-RDI4 funding. These special issues were further discussed with the editorial board, resulting one special issue from the RDI participants as well as another one on methodologies by senior research presenters.

As most of the RDI participants did not have PhDs, and even those with PhDs had obtained them in their later years while working full time, one can surmise that most social work academics have never have been part of a large inter-disciplinary, government funded, research project. The enterprise of conducting a multi-year research study with a large scope, which brings together perspectives of several social science researchers to consider questions about a social problem, and many $\mathrm{PhD}$ students who are learning how to conduct large studies, often has not been experienced by social work academics in the UK. The hope in offering the research mini-placements was that some RDI participants could get a taste of that experience. 
There was positive feedback from the non-social work senior social sciences researchers who hosted the mini-placements. During the project year, relationships were formed or strengthened between UK researchers who had never met a social worker interested in research, but who were committed to expanding the research skills of social work academics. They reported mutually beneficial experiences. Perhaps collaborative exchange could be further pursued as a good strategy in the future by ESRC, in which they required cross-fertilization of disciplines in large bid applications to better answer complex applied social research questions. With high quality professional education come high teaching loads and supervision of placements, resulting in a risk of insularity and isolation of social work academics from other social science researchers. This challenge is unfortunate because interdisciplinary research teams benefit from having social work researchers on large, multi-year government funded studies. There could be mutual and reciprocal enhancements, given the many years of practitioner experiences of most mid-career UK social work academics have to share especially related to disparities research.

The ESRC funding of an RDI specifically for mid-career social work academics was able to be used to leverage wide-ranging benefits highlighting that social work is indeed a part of the research community. The ESRC investment generated generous gifts of time, knowledge and expertise by those senior researchers who sponsored the 22 research mini-placements and the 32 senior researchers who presented at the 5 RDI social work research conferences. These non-reimbursed offerings to the development of research knowledge, skills and attitudes of mid-career social work academics would not have happened without the excellent ESRC reputation in the larger research community.

The access and exposure to this professional generosity by senior researchers was a springboard to building bridges of mid-career social work academics with social science senior researchers and the senior generation of social work research academics. There were examples of building social capital, trusting, mutual and reciprocal relationships, within the community of researchers. The repeated positive social/ professional encounters (ending in the hotel overnight and the celebration dinner) build both 'bridging' and 'bonding' social capital. Bridging stronger relationships across university social work departments and 'bonding' social capital with a gradual social identity of a somewhat cohesive group of RDI participants who had a shared experience. Feelings of being a part of that group varied depending on days of involvement chosen by participants. For those with a high dosage of protected time devoted to the enterprise of research choices offered, reported more feelings of connection to the group and more positive 'norming' around research.

In times of stress, it is relationships which can help us to keep going and be effective. New research on cortisol levels as a measure of stress, confirm that it is spending time with caring relationships which can bring the stress levels down (Gerhardt, 2005). In addition to using this research on relationship for our social work clients, e.g. building networks of caring relationships, i.e. social capital, for stressed and 
vulnerable families (Terrion, 2006), social worker might consider applying concepts of social capital for our own stressed and isolated profession.

In this regard, however, the first step is the provision of 'protected time' for midcareer social work academics to enable focus on increasing their research knowledge, skills and awareness. This first step should be more widely supported.

However, to have 'protected time' without access to supportive network of colleagues also committed to research activities may not be sufficient. In this initiative, the 'protected time' was combined with a menu of research opportunities from which to choose. The structured experience achieved the anticipated aims, as well as an unexpected additional result for the participants: the systematic building of increased 'social capital.' The social capital has established norms of positive attitude towards social work research, as well as both 'bonded' and 'bridging' relationships. This could function to reduce professional stress and isolation levels as social work academics.

The participants reported the immediate positive impact of their University, JUC SWEC and the ESRC investment and expressed gratitude in their evaluation forms to the ESRC, the wider research community, and the leaders of social work education in UK who all worked together to support this effort. This is a rather critical time of transition for the UK social work profession and especially in its developing relationship to research.

'In 1977, the scope of social work research was summarized as an inquiry into the causes of poverty, measurement of the distribution of poverty, surveys of social movements, quantification and indexing of social work, evaluation research into the effectiveness of the social services, and studies of multi-problem families.

Whereas, modern social work research includes descriptive studies of social environments of individual clients and families; descriptive studies of psychological states of individual clients and their families; descriptive studies of social units such as neighbourhoods and large urban environments; descriptive studies of patterns of deviant behaviour; organizational studies; epidemiological surveys; process studies of interventions; and effectiveness studies of interventions' (Soydan, 2010).

The sustained impact of the RDI project would come through their teaching of research to their student social workers. This will be in the form of classroom instruction, as well as referring to research journal articles for the students to read, rather than only books. By having the mid-career social work academics publish in a special issue of a peer review journal, the hope is that they will encourage their students to read the articles they have written. 


\section{Summary}

This RDI project evaluated the funded pursuit of additional research knowledge, skills and positive attitudes by mid-career UK social worker academics with years of practice experience. In some countries, most social work academics have PhDs, usually achieved before the age of 35 , with strong methodological research skills. Their teaching of social work students to become good practitioners may be compromised, however, by their own lack of professional experience in the application of theory and research into practice and personal case examples. They may not understand the importance of requiring service user involvement in research, teaching and practice (Beresford, 2001) for improved empathy of the professional. In addition, their research may not answer the questions most important to practitioners in the field, resulting in practitioners not using it.

This contrast becomes most dramatic in the area of moving forward research agendas for social work in the UK. The field needs more social work research. If PhD studentships in the UK were well-funded for mid-career professionals, that might help to correct this imbalance. More awareness within the social science research community of the value of a social work practitioner-researcher's knowledge might increase collaborative research. Social worker academics are grounded in practice knowledge of community based services, social ecologically situated, conflicted family relationships and experienced in engaging socially marginalized populations. Every collaborative interdisciplinary research team committed to reducing health, education and social care disparities or testing interventions could benefit from social work practitioner-researchers for their unique contributions and understandings of social justice.

Another option is providing 'protected time' for mid-career UK social work academics and offering them a structured menu of learning opportunities over a period of time within a supportive network of relationships. Exposure to enthusiasm of senior researchers should increase social worker academics' interest in testing interventions based on theory and social justice with rigorous research methods. Results of this evaluation supported the benefits of that approach.

\section{References}

Beresford, P. (2001) Service users and research. Research Matters, (April/October), 57-60.

Brannen, J. (2005) 'The entry of qualitative and quantitative approaches into the research process', International Journal of Social Research Methodology, 8, 3.

Bryman, A (2007) Barriers to integrating quantitative and qualitative research. Journal of Mixed Methods Research, 1, 8-22.

Cozolino, L. (2006) The Neuroscience of Human Relationships: Attachment and the developing social brain. London: W.W. Norton 
Fisher, M. and Marsh, P. (2003) Social work research and the 2001 Research Assessment Exercise: An initial overview. Social Work Education 22, 1, 71-80.

Fox, M., Martin, P., and Green G. (2007) Doing Practitioner Research. London: Sage

Freire, P. (1995). Pedagogy of Hope: Reliving Pedagogy of the Oppressed. New York: Continuum.

Gerhardt, S. (2005) Why Love Matters. Londn: Brunner-Routledge

Henderson, P. and Thomas, D. (2002) Skills in Neighbourhood Work. (3rd ed.). Abingdon: Routledge

JUCSWEC (2006) A Social Work Research Strategy in Higher Education: 2006-2020, Joint Universities Council for Social Work Education Committee's Research Sub-Committee [accessed at http://www.swap.ac.uk/research/strategy.asp

International Federation of Social Work (2000) Definition of Social Work at: http://ifsw.org/policies/definition-of-social-work/

McDonald, L., Fitzroy, S., Fuchs, I., Fooken, I., and Klasen, H. (2012). Strategies for high retention rates of low-income families in FAST (Families and Schools Together): An evidencebased parenting programme in the USA, UK, Holland and Germany. European Journal of Developmental Psychology, 9, 1, 75-88.

Macdonald, G. (2003) Using Systematic Reviews to Improve Social Care, London: Social Care Institute for Excellence

Mills (2006) Demographic Review of the UK Social Sciences. Swindon: ESRC.

Orme, J. (2003). Why does social work need doctors? Social Work Education 22, 3, 541-554

Orme, J. and J. Powell (2005) Research Strategy for JUC SWEC: Building Research Capacity: Student Training and Staff Development. London: King's College, Social Care Workforce Research Unit Payne, M. (2005). Modern Social Work Theory. Adershot: Palgrave Macmillan

Putnam, R.D. (2000) Bowling Alone: The collapse and Revival of American community. New York: Simon \& Shuster

Saracostti, M., (2007) Social capital as a strategy to overcome poverty in Latin America: An overview. International Social Work. 50, 515-532

Shaw, I. \& Norton, M. (2006) The Kinds and Quality of Social Work Research in UK Universities, York: University of York.

Shaw, I., Briar-Lawson, K., Orme, J. and Ruckdeschel, R.( Eds.) (2010) The Sage Handbook of Social Work Research. New York: Sage

Shemmings, D. (2006) 'Quantifying' qualitative data: An illustrative example of the use of Q methodology in psychosocial research. Qualitative Research in Psychology, 3, 2, 147-165.

Soydan, H. (2010) Politics and values in social work research. in I. Shaw, K. Briar-Lawson, J. Orme, and R. Ruckdeschel (Eds.) The Sage Handbook of Social Work Research. New York: Sage (pp. 130-148)

Terrion. (2006) Building social capital in vulnerable families: Success markers of a school-based intervention program. Youth and Society. 38, 2, 155-176

Werner, E.E. and Smith, R.S. (1992) Overcoming the Odds: High risk children from birth to adulthood. Cornell, NY: Cornell University Press

Wilkinson, R. and Pickett, K. (2009) The Spirit Level: Why equality is better for everyone. London: Penguin Books 